\title{
Using the system-functional approach to assess the development of housing construction
}

\author{
Mariia I. Ermilova ${ }^{1, *}$, and Sergey V. Laptev ${ }^{1,2}$ \\ ${ }^{1}$ Plekhanov Russian University of Economics, Department of financial management, 117997, Moscow, Russia \\ ${ }^{2}$ Department of Corporate Finance and Corporate Governance, University under the Government of the Russian Federation, 125993, \\ Moscow, Russia
}

\begin{abstract}
The article substantiates the methodology of the system-functional approach to organizing financing and ensuring the functioning of the complex, the use of which allows you to quickly identify and eliminate the factors of non-market distortions in the development of the housing complex and increase the efficiency of its functioning. The possibilities of practical application of the methodology at different levels of the organization of the economy are revealed The most powerful distorting effects arising from the redistribution of incomes created by market participants that do not correspond to their role in economic processes, due to a violation of the proportions of reproduction, the formation of incentives to obtain nonmarket income are highlighted.
\end{abstract}

\section{Introduction}

Good housing finance management is a market organization, complemented by direct government funding and financial support, that ultimately maximizes the benefits of housing construction for consumers and maximizes the positive effects of housing and the housing market on economic development.

The aim of the study is to develop a theoretical model for maximizing direct benefits for consumers of housing services and indirect benefits from this organization for the population and to show the possibilities of using this model in practice.

Objectives of the article:

- to analyze the existing approaches to the organization and improvement of housing construction financing, substantiating the necessity and rationality of this improvement on the basis of a system-functional approach;

- to identify methodological grounds for the implementation of a system-functional approach to the organization of housing finance;

- to carry out a system-functional analysis of the development of the housing complex, establishing the possibilities and limitations of this development.

Due to the unity of financing the housing complex, its constituent parts act in economic relations as relatively isolated parts of the housing complex. The mortgage complex stands out as such a part.

At present, it is necessary to develop a new strategy for the development of the mortgage complex in Russia, which would consider all the features of the "postcentralized economy". (Loginov M.P., Loginova O.N., 2009).
In the process of researching a housing complex, almost all authors highlight the market part of the complex and its state funding and regulation. The housing market, as a part of the housing complex, "provides for the legally established transfer of ownership rights to housing objects from some individuals or legal entities to others" (Samarukha V.I., Krasnova T.G., Shalygina T.V., 2009). The interpretation by the authors of the nature of the relationship between the market self-organization of the housing complex and its state regulation and financing is of great importance for understanding the organization and functioning of the housing complex, developing proposals for its improvement.

The traditional understanding of the nature of this interconnection is brought into the sphere of the housing complex from the standard courses of economic theory. This is how the market is interpreted as a spontaneous order, which independently, without the help of the state, constantly poses and finds answers to five fundamental questions of the organization of the economy: 1. How much should be produced? 2. What should be done? 3 . How should these products be produced? 4. Who should receive these products? 5 . Is the system able to adapt to changes? (McConnell C.R., Bru S.L., 1992).

Another important question is what does the state do in a market economy? "In the course of economic activity, society faces two questions: who should ensure the «rules of the game» and insure market failures? ... In economic theory, there is agreement only on the first issue. On the second question, the range of opinions is very wide and can be reduced to two extreme points of view:

\footnotetext{
* Corresponding author: masha080487@ mail.ru
} 
1) According to the neoclassical and neoliberal direction, the market economy has the ability to selfregulation due to its inherent economic freedom and competition and therefore does not need state intervention, and the role of the state in the economy should be minimal and reduced to supervision over the observance of the rules of the game;

2) From the point of view of the Keynesian direction, the market economy has imperfections, to mitigate which the market mechanism must be supplemented by government regulation ...» (Macroeconomics, 2015).

Realizing that it will not be possible to reach a final resolution of the dispute between different areas of modern economic theory in a separate article, we, nevertheless, will express our arguments regarding the noted disagreement. The question should be posed as follows: can a modern market economy or its parts, subsystems independently eliminate and resolve problems and contradictions without the support and assistance of the state? This question in relation to a specific object of research can be formulated as follows: can the system of financing the housing complex independently, without state support, perform functions inherent in finance in a market economy at a level that allows business entities to conduct business completely independently and efficiently? Let's try to give a reasoned answer to this question.

Many modern economists believe that the state, through the system of state financing and regulation, at least compensates for the following market failures: regulation of the money supply, anti-cyclical and anticrisis regulation of the economy, and solving social problems. The traditional idea of the active role of finance (financing) in a market economy is reduced to the following main functions: 1 . Allocation of resources; 2. Formation of material conditions for reproduction; 3 . Incentives; 4. Economic regulation. However, the economic and financial systems are constantly evolving. The financial system has new functions in relation to the economic system, for example, the following: 5 . Maintaining the liquidity of payments and ensuring business flexibility; 6 . Strengthening market signals; 7. Reallocation of money over time in favor of effective entrepreneurial and innovative projects; 8 . Protection from risks.

One of the most important functions of the state is the constant change, improvement of the rules of the game, without which the economy, formally market, according to market principles, can no longer function. A. Smith, a classic of liberal theory, advocated private property and economic freedom because private entrepreneurs, guided by their desire for profit, increased the total income of society, that is, the national income (Smith A., 1962). The unity of interests of all members of society was ensured by the fact that the generated income was distributed according to certain norms. Therefore, according to his idea, it was impossible to increase the total income of the entrepreneur and at the same time reduce the wage rate. "The most sacred and inviolable right of property is the right to one's own labor, for labor is the original source of all property in general. All the property of a poor man lies in the strength and dexterity of his hands, and to prevent him from using this power and dexterity as he considers himself convenient, if only he does not harm his neighbor, then directly encroach on this sacred property "(Smith A., 1962).

The essence of the concept of economic liberalism boils down to the following:

1) creation of conditions for ensuring the protection and normal (business or labor) realization of property rights by all participants in economic activity, protection of property rights means, among other things, the protection of rights to income from property;

2) the protection of rights creates the economic freedom necessary for effective activity;

3 ) the economic freedom of all owners ensures an increase in the aggregate welfare, when other people's rights are not violated, including the right to income, under this condition everyone seeks to create additional income. The ability of the owner of great power to redistribute other people's incomes in his favor, violating the property rights of the persons concerned, deprives him, at least in part, of the motivation for intense entrepreneurial activity. Those whose rights are violated also lose motivation to act effectively and responsibly.

4) the redistribution of income based on the abuse of economic or state power deprives all participants in economic activity of a genuine interest in increasing income based on effective economic activity and a true responsibility for this increase. At the same time, the very spirit of the liberal concept and the essence of the market organization of the economic space suffers damage. Therefore, in order to restore the spirit of liberal freedom and restore the curved market economic space, the possibility of non-market redistribution of income must be blocked by changing institutional rules. Without this, the spirit of the liberal concept cannot be preserved, and the efficiency of the market economy cannot be restored.

It turns out that when the basic distribution function of finance is distorted, the stimulating function also does not work for the effective development of the housing complex, since economic incentives are not manifested to the proper extent, they induce resource owners not to entrepreneurial activity, but to activity in the sphere of income redistribution in their favor. Salaried workers are not properly motivated to work efficiently, because their wages do not reflect real merit in generating aggregate income at the enterprise. But when income distribution is distorted, and reproduction proportions turn out to be worse than optimal. With an uneven distribution of income, many goods, including durable goods, are inaccessible to the bulk of the population. With limited demand, the pace of economic development turns out to be significantly lower than possible.

\section{Methods}

The study of the organization of management of housing construction is one of the specific and typical tasks of economic science. The usual approach to the formulation and solution of such problems is to study the systems or 
mechanisms of management of carefully and scrupulously one or another economic process in a particular sector of the economy of a particular country.

It is required to create intermediate theoretical constructions between the general principles of economic science and specific forms of management and management methods in relation to the analysis and assessment of the object of research - the housing complex and the system of its financing, it is advisable to critically analyze the experience of K. Marx, who, as you know, created the concept of socio-economic development of society on the basis of consistent movement, the transition from one mode of production to another. At the same time, he defined relations of production as a form that organizes the process of development of a mode of production, the content of which he defined the productive forces (K. Marx).

Unsuccessful components in the implementation of the explanatory, predictive and practical transformative concept of K. Marx are associated with the following circumstances.

First, K. Marx's idea of the communist mode of production as the highest stage in the development of human civilization in comparison with capitalism turned out to be erroneous.

Secondly, K. Marx's assessment of the importance of specific production relations of each mode of production as the main ones that determine the nature and dynamics of development of the productive forces also turned out to be erroneous. Marx underestimated the importance of economic relations common to several modes of production. These relations ensure the continuity of economic development, the relative smoothness of the transition from one type of economic system to another. Excessive exaggeration of the role of production relations specific to individual modes of production, which were qualitatively and significantly different from the specific production relations of the previous mode of production, led to Marx's understanding of the transition from one mode of production to another as extremely violent, inevitably associated with a social revolution, which also turned out to be incorrect.

Thirdly, K. Marx's idea of the totality of production relations as a certain general form for all processes of development of the productive forces also turned out to be inaccurate and essentially wrong. As it turned out, different production relations act in different ways on the productive forces, influencing different characteristics and parameters of their development. Different production relations turned out to have different bases, so the idea that the entire system of production relations of one mode of production at the same historical time changes to a radically different system of production relations (the system of production relations of the next mode of production) was also wrong. It is no coincidence that the attempts made by Soviet economists in the pre-market era to logically build a unified system of production relations of the socialist economy, deriving these relations from some common basis - the fundamental economic relation - did not end in a successful, uniform solution recognized by all scientists.
Fourthly, it turned out that production relations are structured into a certain unified form of productive forces not by themselves, but together with social and economic institutions, organizations that direct and regulate their actions. Therefore, a systematic approach to understanding the interaction of production relations and productive forces from the standpoint of today is to consider the process of the impact of production relations on productive forces in unity with the economic institutions and organizations that direct their functioning and regulation. At the same time, relations, institutions, and organizations are combined into a system according to the functional principle, that is, according to what separate action they produce on the productive forces. Accordingly, within the framework of a certain function, as some organizing form, they direct the development of productive forces and economic processes. Within this form, its individual components are organized into unity based on some general principles. Accordingly, by how these general principles are embodied in economic practice, one can judge how effective the organization of the form components is, how well it contributes to economic development.

\section{Results and Discussion}

Within the framework of the system-functional approach, on the one hand, the interaction with production relations not only of the entire system of the productive forces of a given society, but also of a separate subsystem of this system, for example, the productive forces of the housing complex, can be considered. On the other hand, as a form of development of productive forces, not the entire set of production relations of a given society, acting on the development of productive forces in different directions and not possessing a genuine internal systemic unity, should be considered, but a separate production relation or a group of production relations connected with each other, which arose and develops as some integral unity and performing in its totality the same functions in relation to the system or subsystem of productive forces. Within this limited group of functions, a separate production relation or a related group of production relations (jointly performing these functions) is a truly internally homogeneous form of organization of productive forces, in relation to which the methodology of systemfunctional analysis can be applied.

At the same time, it becomes possible to consider not only individual abstract constructions - a production relation or a group of related production relations, but a given relation or a group of relations in the unity of its interaction with socio-economic institutions, business entities and bodies of their socio-economic regulation (within the functions that they do). This approach makes it possible to identify, within a single form (as a structure), the complex action on the productive forces of all its internal elements, without isolating - at least up to a certain point - the individual action of each of the form elements. The latter is associated with additional analytical, factual, statistical difficulties and is far from 
always justified in a specific economic analysis. In a concrete analysis, only the result of the complex action on the productive forces of all elements of the form can be taken into account.

The use of system-functional analysis allows one to give not only a quantitative, but also a qualitative assessment of the development of a particular system or subsystem of productive forces. A qualitative assessment is associated with determining how the productive forces develop: in accordance with the economic content of the functions inherent in the organizing form, or not. In the first case, this means that the selected separate production relation or group of relations adequately fulfills its role in organizing the development of productive forces, not allowing various kinds of external disturbing factors to bring their destructive influence into this development organization. Accordingly, the development of productive forces (within these functions) will be dynamic and efficient. In the second case, when the productive forces develop completely or largely not in the directions determined by the functions of production relations, it is necessary to determine the causes and source of destructive disturbing actions external to the system of interaction of productive forces and the forms of their development. Having identified the causes and source of destructive disturbing actions, it is necessary to find ways to eliminate, or at least significantly weaken these actions in practice.

Each production relation or related group of production relations is an organizing form of development of the productive forces, but only within the limits of the functions that he or she performs in the economic system. Since different production relations perform different functions, this makes it possible to clearly identify the influence of each individual production relation on the development of productive forces (society as a whole, one or another industrial sectoral or territorial complex), to determine the disturbing destructive influences of external ones, not related to this relation or group. relations of disturbing factors.

As a result of the carried out extended, complex system-functional analysis, it is possible to clearly determine which specific production relations are insufficient to ensure dynamic and effective development, within which functions it is insufficient, by what external destructive disturbing factors this action is weakened or deformed, and by what specific ways and using methods, this action can be restored and strengthened to a potentially possible level.

\section{Conclusion}

From the standpoint of the system-functional approach, the impact of the existing system of financing the housing complex on its functioning and development hinders the normal, effective implementation of key functions of finance in market conditions. Restrictive institutional regulation is intended to reduce the distribution of income in a complex according to the levels of power and economic strength. Institutional regulation that actively supports the implementation of market principles is designed to make it easier for market entities to fulfill their functions. For example, if a network of information and consulting centers is created in the Russian regions within the framework of the system of state and municipal services that help home buyers identify and objectively assess the key and most significant characteristics of the usefulness of housing, the housing market will become more transparent and efficient.

\section{References}

1. N.A. Gattunen, Publ. fin., 19 (451) (2011).

2. N.B. Kosareva, Polidi et al. Econ. Issues, 7 (2019).

3. S.A. Krymov, Bullet/of Moscow Univ. Series 21 Management (state and society), 1 (2010).

4. A.V. Krysin, Prop. Relat. in the Rus. Fed., 11 (122) (2011).

5. M.P. Loginov, O.N. Loginova, Mon. and cred. 3 (2010).

6. C.R. McConnell, S.L. Bru, Economics: Principles, Problems and Policy. M.: Republic (1992)

7. A.S. Bulatov, Macroeconomics: a textbook for applied bachelor's degree, (Yurayt Publishing House, 2015).

8. K. Marx. F. Engels, Soch. 2nd ed. T.13.

9. V.Ya. Orlov, V.F. Gareev, Rus. Jour. of Entrepren., 9 (2010).

10. V.I. Samarukha, T.G. Krasnova, T.V. Shalygina, Vestnik IGA, 3 (65) (2009).

11. A.M. Smith, Publishing house of Socio-economic literature, (1962).

12. J. Stiglitz (Moscow: Eksmo, 2016). 